\title{
FREQUENCY OF CAUSATIVE BACTERIA IN URINARY TRACT INFECTION IN CHILDREN
}

\author{
Rifayat Ullah Afridi ${ }^{1}$, Aneela Ambreen ${ }^{1}$ and Kashif ${ }^{1}$
}

1. Naseer Teaching Hospital

\section{ABSTRACT}

Objective:

This study was designed to know frequency of different bacteria causing urinary tract infection in children in our region.

Study design: case series

Place and duration of study:

This study was performed in Pediatric department of Naseer Teaching Hospital Kabir Medical College Peshawar, from august 2011 to January 2014.

\section{Methodology:}

A total of 550 sample of urine were sent for culture and sensitivity, of which 100 cases were found positive for bacterial growth. Urine samples have been collected with care from preventing from contamination by different techniques like mid stream urine collection, suprapubic aspirate and catheterization in few cases. Bacterial growth of $10^{5}$ or more were consider positive growth.

\section{Results:}

our results showed that E-coli was the most common bacteria causing UTI in $66 \%$ of cases, followed by klebsheila (14\%), proteus(12\%) and staphaureus(5\%).Pseudomonas, Enterobacter and entrococcus were present in $1 \%$ cases each. Uti was common in females (58\%) than male $(42 \%)$.

\section{Conclusion:}

UTI is common problem in all age groups of children-coli are the most common pathogen causing UTI. Females are having more common this problem than male, while in infancy males are more prone to UTI as compare to female.

Key words: Bacteria, urinary tract infection, children.

\section{INTRODUCTION}

Urinary tract infections (UTIs) are among the most common bacterial infectious diseases encountered in medical clinical practice and account for significant morbidity and high medical

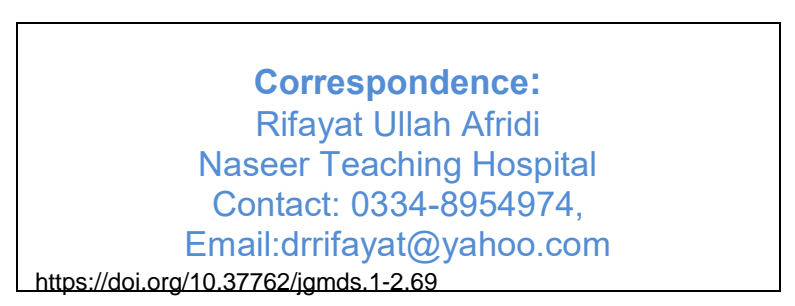
costs. A urinary tract infection (UTI) is a bacterial infection that affects part of the urinary tract. When it affects the lower urinary tract it is known as a simple cystitis (a bladder infection). Alternatively, it may involve the upper urinary tract, in which case it is known as pyelonephritis. If the urine contains significant bacteria but there are no symptoms, the condition is known as asymptomatic bacteriuria ${ }^{1}$. The incidence of UTI in girls is estimated to be $3 \%$ and in boys around $1 \%^{2}$. Up to $7 \%$ of girls and $2 \%$ of boys will have a cultureproven symptomatic UTI by age 6 years $^{3}$. 
In young children, the only symptom of a urinary tract infection (UTI) may be a fever. Because of the lack of more obvious symptoms, when females under the age of two or uncircumcised males less than a year exhibit a fever, a culture of the urine is recommended by many medical associations. Infants may feed poorly, vomit, sleep more, or show signs of jaundice. In older children, new onset urinary incontinence may occur ${ }^{4}$. The most common causative agents of UTI are E.coli, Klebsiella, Pseudomonas, other Gram negative enteric bacilli (such as Proteus) and other agents such as group B streptococci, staphylococci, Candida albicans and microorganisms belonging to flora of vagina and periurethral region ${ }^{5}$. Escherichia coli is the most prevalent causative organism of UTI and is solely responsible for more than $80 \%$ of these infections. An accurate and prompt diagnosis of UTI is important in shortening the disease course and for preventing the ascent of the infection to the upper urinary tract and renal failure ${ }^{6}$. Over the last decade there has been a substantial increase in resistance of uropathogens to antibiotics. Resistance rates among $\mathrm{S}$. aureus strains are increasing, and a major part of this species has become resistant to $\beta$-lactamase resistant penicillins ${ }^{7}$.

\section{METHOLOGY}

This study was carried out at department of pediatrics Naseer teaching hospital, Kabir medical college Peshawar from august 2011 to December 2014.Patients included in this study were both from ward and out department patients (OPD) unit. A total of 100 patients were included in the study. All cases were from neonatal age to 13yrs. All children were divided into 3 groups. Group 1 include cases from age 0 to 1year,group 2 from age 1 to 3 year, and group 3 from age 3 to 13 year. All data was recorded on a predesigned proforma including detail history, clinical examination and investigations. All cases including in study were having UTI confirmed with urine culture. Urine samples were collected by different methods like mid strem urine sampling, suprapubic aspiration and catheterization. Urine sample were send for culture sensitivity to microbiology section of Naseer Teaching Hospital. All culture positive cases were included in the study. The study had necessary approval from the Institutional Ethical Committee and informed consent was taken from the parents/guardian of the subjects. The data was transferred and analyzed using statistical package for social sciences (SPSS) version 10. The results were presented in the form of percentages; chisquare test was applied for comparison of proportions with significance of $p$ - value less than 0.05 .

\section{RESULTS}

A total of 100 cases of urine culture positive cases of UTI were selected for this study. Our results have shown that $\mathrm{E}$ - coli was the most common bacteria isolated in $66 \%$ of cases. Klebsheila was the second most common bacteria isolated in $14 \%$ of cases, followed by Poteus and Staph aureus in $12 \%$ and $5 \%$ of cases respectively. Pseudomonas, Enterobacter, and Enterococcus were isolated in $1 \%$ of cases each. UTI was found more common in females (58\%) than males $(42 \%)$. Although in infants UTI was more in males as compared to female (figure1).

\section{Table-1. Frequency of causative bacteria in UTI}

\begin{tabular}{|l|l|}
\hline Causative bacteria & Percentage \\
\hline E-coli & $66 \%$ \\
\hline Klebsheila & $14 \%$ \\
\hline Proteus & $12 \%$ \\
\hline Staph aureus & $5 \%$ \\
\hline Pseudomonas & $1 \%$ \\
\hline Enterococcus & $1 \%$ \\
\hline Enterobacter & $1 \%$ \\
\hline
\end{tabular}

Table-2. sex distribution 


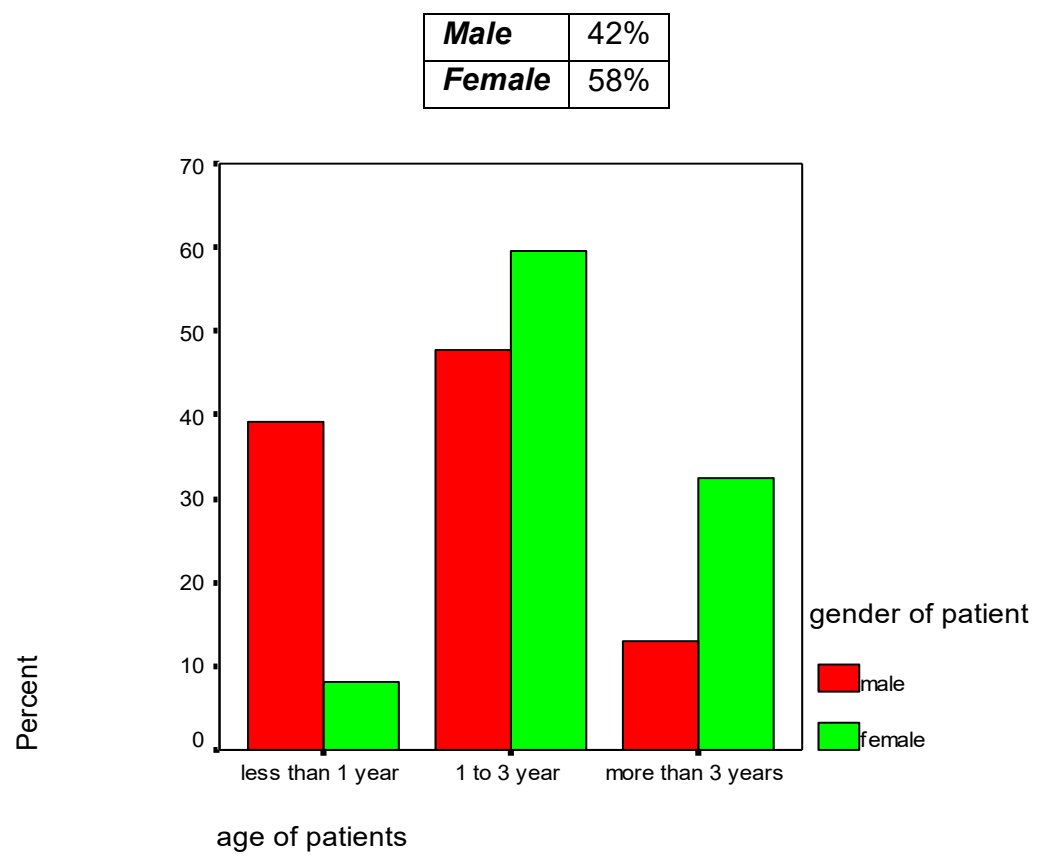

Figure-1: different age groups and sex distribution.

\section{DISCUSSION}

Microbial infection of the urinary tract is one of the most common infectious diseases worldwide. In this study, of 550 patients from who urine samples were taken, only $18.2 \%$ had a positive urine culture growth of bacteria. This is possibly because UTI symptoms are not a reliable indicator of infection and in children younger than 2 years of age are non-specific.

Although the prevalence of pathogens in different parts of the world is somewhat similar, antimicrobial resistance patterns reported from different regions are significantly different and antimicrobial resistance is increasing. The results of our study show that among the heterogeneous causative organisms of UTI,Gram negative bacteria are the predominant pathogens, followed by Gram-positive cocci. These findings are consistent with reports published from other countries ${ }^{8}$.Ecoli was the most common bacteria isolated in $66 \%$ of cases in this study, which is consistant with many studies. Farajnia et al concluded that E-coli is isolated in $74 \%$ of cases followed by klebsheila in $11 \%$ of cases, near similar to our results ${ }^{9}$. Klebsheila was isolated in $14 \%$ of cases in our study which was second most common bacteria after E-coli as in Farajnia et al.

Proteus was third most commonly isolated bacteria in $12 \%$ of cases in our study. Kang YD et al results showed that proteus is $3^{\text {rd }}$ most common bacteria isolated in $2.1 \%$ of cases followed by Ecoli and klebsheila as in our case ${ }^{10}$. Although frequency of proteus is more in our study as compare to Kang YD et al, which may be due to geographical distribution of microorganisms. Staph aureus has been isolated in $5 \%$ of cases which is near similar to results of Farajnia et al, isolated in $6 \%$ of cases. Pseudomonas enterobacter and enterococcus were isolated in $1 \%$ of cases each.

\section{REFRENCES}


1. Lane, D.R. and S.S. Takhar, 2011. Diagnosis and management of urinary tract infection and pyelonephritis. Emergency medicine clinics of North America, 29(3): 539-52. doi:10.1016/j.emc.2011.04.001.

2. Foxman, B., Epidemiology of urinary tract infections: incidence, morbidity, and economic costs. Dis Mon, 2003. 49(2): p. 53-70.

3. Marild, S. and U. Jodal, Incidence rate of first-time symptomatic urinary tract infection in children under 6 years of age. Acta Paediatr, 1998. 87(5): p. 549-52.

4. Bhat, R.G., T.A. Katy and F.C. Place, 2011. Pediatric urinary tract infections. Emergency medicine clinics of North America, 29(3): 637-53.

5. Jones KV, Asscher AW. Urinary tract infection and vesicoureteral reflux. In: Edelmann CM. (eds). Pediatric Kidney Disease. Second edition. Volume II, Little Brown Company. Boston, Toronto, London 1992; 1943-91.

6. National Committee for Clinical Laboratory Standards Performance standards for antimicrobial disc susceptibility tests(7th ed.)NCCLS, Wayne, Pennsylvania, USA (2000) M2-A7.

7. A.E. Bogaard, N. London, C. Driessen, E.E. Stobberingh .Antibiotic resistance of faecal Escherichia coli in poultry, poultry farmers and poultry slaughterers J Antimicrob Chemother, 47 (2001), pp. 763771.

8. G.G. Zhanel, J.A. Karlowsky, G.K. Harding, A. Carrie, T. Mazzulli, D.E. Low et al.A Canadian national surveillance study of urinary tract isolates from outpatients: comparison of the activities of trimethoprim-sulfamethoxazole, ampicillin, mecillinam, nitrofurantoin, and ciprofloxacin Antimicrob Agents Chemother, 44 (2000), pp. 1089-1092.

9. Farajnia S, Alikhani MY, Chotasiou R,Naghili B, Nakhlband. Causative agents and antimicrobial susceptibility in northwest iran. International journal of infectious diseases. 2009; 13:140-44.

10. Kang YD, Kim NS, Oh SH. Causative Organisms of Urinary Tract Infection in Children, and their Antibiotic Susceptibility.Korean J Pediatr 2004 October;47(10):1065-1071.

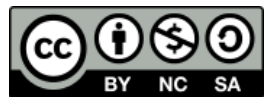

LICENSE: JGMDS publishes its articles under a Creative Commons Attribution Non-Commercial Share-Alike license (CC-BY-NC-SA 4.0). COPYRIGHTS: Authors retain the rights without any restrictions to freely download, print, share and disseminate the article for any lawful purpose. It includes scholarly networks such as Research Gate, Google Scholar, LinkedIn, Academia.edu, Twitter, and other academic or professional networking sites. 